NBER WORKING PAPER SERIES

LIMITING EMISSIONS AND TRADE:

SOME BASIC IDEAS

Kala Krishna

Working Paper 16147

http://www.nber.org/papers/w16147

\author{
NATIONAL BUREAU OF ECONOMIC RESEARCH \\ 1050 Massachusetts Avenue \\ Cambridge, MA 02138 \\ July 2010
}

The views expressed herein are those of the author and do not necessarily reflect the views of the National Bureau of Economic Research.

NBER working papers are circulated for discussion and comment purposes. They have not been peerreviewed or been subject to the review by the NBER Board of Directors that accompanies official NBER publications.

(C) 2010 by Kala Krishna. All rights reserved. Short sections of text, not to exceed two paragraphs, may be quoted without explicit permission provided that full credit, including $\odot$ notice, is given to the source. 
Limiting Emissions and Trade: Some Basic Ideas

Kala Krishna

NBER Working Paper No. 16147

July 2010

JEL No. F18

\section{ABSTRACT}

The computable general equilibrium models used in the literature tend to be a bit of a black box. This paper provides some intuition behind what goes on in these black boxes by laying out a simple general equilibrium model and intuitively explaining what lies behind the demand for emissions. It traces out how a reduction in total emissions allowed in one country aspects the general equilibrium and the determinants of the extent of leakage in the model as well as more generally. It concludes with some implications for policy.

Kala Krishna

Department of Economics

523 Kern Graduate Building

The Pennsylvania State University

University Park, PA 16802

and NBER

kmk4@psu.edu 


\title{
Limiting Emissions and Trade: Some Basic Ideas
}

\author{
Kala Krishna \\ The Pennsylvania State University, CES-IFO and NBER
}

June 18, 2010

\section{Introduction}

On June 26, 2009 the American Clean Energy and Security Act (or the Waxman-Markey Bill after its authors) was approved by the US House of Representatives. It has (in June 2010) yet to clear the Senate. This event marked the first time either house approved a law meant to limit emissions to combat climate change and has resulted in a flurry of economics research in the area. The bill would essentially create cap-and-trade programs for greenhouse-gas emissions and specifies reductions in total emissions of $17 \%$ starting from 2012. See CBO (2009a) for a good summary of the bill and its implications. Recent news indicates that ${ }^{1}$ the Senate version of the Bill will be weaker, with utilities being subject to caps by 2012 but with manufacturers being phased in only by 2016. Also likely are floor and ceiling prices of $\$ 10$ and $\$ 30$ per ton that will be adjusted for inflation ${ }^{2}$. It will have product specific import taxes based on the cost disadvantage created by such cap and trade measures (called border tax adjustments or BTAs for short) on countries that do not limit their emissions. Such BTAs would both level the playing field for US firms and prevent leakage, where leakage is the

\footnotetext{
${ }^{1}$ See the Reuters article, March 15, 2010, entitled "Senate climate bill to set utitlities cap-trade".

${ }^{2}$ The price ceiling would insure that businesses do not face too high a cost of permits as these are part of their costs. The floor protects them from the risk of investing in technology to reduce emisssions only to find that it was not worth their while ex post.
} 
change in foreign emissions as a share of the domestic emissions reductions. They may also be legal under GATT/WTO, see Frankel (2009).

Existing studies suggest that the size of the BTAs would likely be quite small for most products. This is why, as currently drafted, US legislation envisages BTAs mainly for producers in energy-intensive sectors. These include chemicals, paper, ferrous metals, non-ferrous metals, and mineral products. However, estimates of the effect of the kinds of emissions limits being discussed vary quite a bit. Atkinson et. al. (2009), which was a background paper for World Development Report 2010, uses a partial equilibrium model to estimate that if carbon is taxed at $\$ 50$ per ton of CO2, Chinese exports to the US would face an average tariff rate of $10.3 \%$. Mattoo et. al. (2009) employ a multi country computable general equilibrium framework (the Environmental Impact and Sustainability Applied General Equilibrium Model, or ENVISAGE model). They compare outcomes under different scenarios for BTAs of a carbon tax that reduces emissions by $17 \%$ relative to 2005 by all OECD countries. ${ }^{3}$ Their work suggests considerable room for leakage, especially without appropriate BTAs. They calculate that a $17 \%$ reduction in emissions in energy intensive goods only (which is what the US is proposing) would lead to total emissions in 2025 relative to 2005 rising by about $54 \%$ for the world: the $17 \%$ reduction in emissions by the OECD countries is more than undone by low and middle income countries raising their emissions by about $120 \%$ in the absence of BTAs.

The effect of BTAs on emissions and exports is also shown to be sensitive to who is reducing emissions. Boehringer et. al. (2010) suggests that reducing emissions is significantly more costly in the EU than the US mostly because EU emissions are already lower than comparable US ones. Moreover, because the EU is more open than the US, leakage is greater from EU reductions than US ones. Full border tax adjustment policies, which include a tax on imports and a subsidy to exports, are quite effective in reducing leakage, with the import tariff being more important than the export subsidy.

The computable general equilibrium models used in the literature tend to be a bit of a black box. This paper provides some intuition behind what goes on in these black boxes by laying out a simple general equilibrium model and intuitively explaining what lies behind the demand for emissions. It traces

\footnotetext{
${ }^{3}$ Mattoo et. al. (2009) and McKiben and Wilcoxen (2008) among others, argue that whether developing country emissions or developed country ones are used as a basis for the BTA makes a substantial difference to developing country exports, leakage, and world emissions.
} 
out show how a reduction in total emissions allowed in one country affects the general equilibrium and the determinants of the extent of leakage in the model and more generally. Finally, it concludes with some implications for policy.

\section{Emissions in a General Equilibrium Setting}

Consider a perfectly competitive world with constant returns to scale where all inputs are essential for production. There are two final goods, one which needs emissions as an input (the dirty good) and the other which does not (the clean good), and a non traded intermediate good. ${ }^{4}$ Let, $x$ and $Y$ denote the domestic output of the dirty and clean good. The dirty good is made using the intermediate good, $X$, which in turn is made using capital and labor, and emissions, $Z{ }^{5}$ The clean good, $Y$, is made using capital and labor. The total endowments of capital and labor are exogenously given and denoted by $K$ and $L$ respectively. Preferences are assumed to be identical and homothetic. This ensures that demand is linear in income so that the relative demand for goods is independent of income and depends only on relative prices. As a result, the demand side can be treated as if it arises from a single aggregate consumer with these same preferences but endowed with the aggregate income. ${ }^{6}$

As there are constant returns, we can define the cost of a unit of the good independent of scale. These unit cost functions for $X, x$ and $Y$ are denoted by $c^{X}(w, r), c^{x}\left(p^{X}, \tau\right)$, and $c^{Y}(w, r)$ respectively, where $w$ and $r$ are the price of labor and capital, $p^{X}$ is the endogenously determined price of the non traded intermediate, and $\tau$ is the price of a unit of emissions. Due to perfect competition, price equals marginal cost (which also equals average cost), for each good. Thus, the price of the intermediate good equals its cost.

$$
p^{X}=c^{X}(w, r) .
$$

${ }^{4}$ As the intermediate is non traded and essential for production of $x$, its price adjusts to ensure it is produced when the economy is notspecialized in $Y$. .

${ }^{5}$ Different combinations of the intermediate and emissions can be used to make a unit of output. The choice of where to be on the unit isoquant comes from cost minimization on the part of the firm and due to the assumptions made depends only on $\frac{\tau}{c^{X}(w, r)}$ rather than $w, r$, and $\tau$ separately.

${ }^{6}$ The model presented below is similar to that of Copeland and Taylor (2003). It is less general as there is no joint production allowed, but more general as no functional form assumptions are made. 
If all emissions permits are sold and there are no tariffs or other taxes, then the domestic price of $x$ and $Y$ equals the world price and this equals unit cost so

$$
p^{x}=p^{* x}=c^{x}\left(c^{X}(w, r), \tau\right)
$$

and

$$
p^{Y}=1=c^{Y}(w, r)
$$

as we take $Y$ as the numeraire good.

The dark curves in Figure 1 depicts equations (3) and (2) for a given $\tau$. As the unit cost function is concave in factor prices, this curve looks much like an indifference curve. Its slope at a given $\frac{w}{r}$ gives the capital labor ratio in the sector. ${ }^{7}$ Totally differentiating equation (2) and (1) shows that for a given $\tau$, the slope of the curve depicting equation (2) has the same slope as that of the curve depicting equation (1) along any ray from the origin. The curve depicting equation (2) is steeper than that depicting equation (3) as we depict the case where $X$ (and hence $x$ ) is capital intensive relative to $Y$. Finally, an increase in $\tau$ would reduce the $w$ and $r$ consistent with equation (2) for a given $p^{x}$ so that the curve depicting equation (2) would shift inwards as depicted by the dashed line in Figure 1.

Given $p^{* x}$ and $\tau$, we get $w$ and $r$ from equation (2) and (3) assuming no specialization. This corresponds to the point $A$ in Figure 1. Then equation (1) gives $p^{X}$. Once we know $w, r$, and $p^{X}$, we know the unit input requirements of input $i$ in $j\left(a_{i j}().\right)$. For factor markets to clear total demand for each factor (which equals demand from making $X$ and $Y$ ) must equal total supply denoted by $L$ and $K$. Hence

$$
\begin{aligned}
a_{L X}\left(\frac{w}{r}\right) X+a_{L Y}\left(\frac{w}{r}\right) Y & =L \\
a_{K X}\left(\frac{w}{r}\right) X+a_{K Y}\left(\frac{w}{r}\right) Y & =K .
\end{aligned}
$$

${ }^{7}$ Totally differentiating equation (1) gives

$$
\begin{aligned}
d p^{X} & =c_{w}^{X}(w, r) d w+c_{r}^{X}(w, r) d r \\
& =a_{L x}\left(\frac{w}{r}\right) d w+a_{K x}\left(\frac{w}{r}\right) d r .
\end{aligned}
$$

using the envelope theorem. Thus, the slope of the unit cost curve is

$$
\frac{d w}{d r}=\square \frac{a_{K x}\left(\frac{w}{r}\right)}{a_{L x}\left(\frac{w}{r}\right)}=k^{X}
$$

where $k^{X}$ denotes the capital-labor ratio in $X$. 
Figure 1: Determination of Factor prices

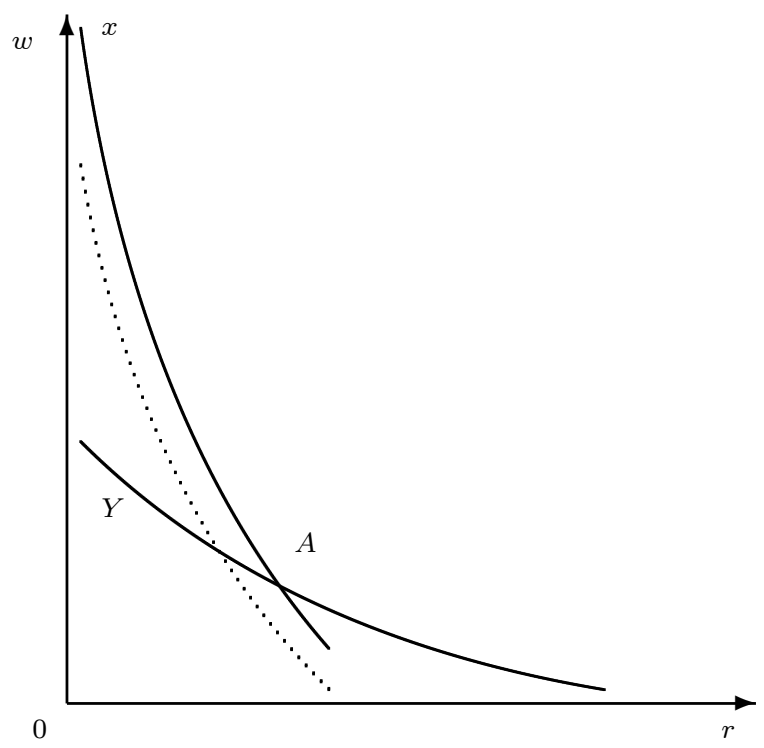

Since the intermediate good is non traded, its demand (as an input in making $x$ ) equals supply $(X)$ in the country so

$$
a_{X x}\left(\frac{c^{X}(w, r)}{\tau}\right) x=X
$$

Substituting for $X$ from equation (6) into equations (4) and (5) gives

$$
\begin{aligned}
a_{L X}\left(\frac{w}{r}\right) a_{X x}\left(\frac{c^{X}(w, r)}{\tau}\right) x+a_{L Y}\left(\frac{w}{r}\right) Y & =L \\
a_{K X}\left(\frac{w}{r}\right) a_{X x}\left(\frac{c^{X}(w, r)}{\tau}\right) x+a_{K Y}\left(\frac{w}{r}\right) Y & =K .
\end{aligned}
$$

Thus, given $p^{* x}$ and $\tau$, equations (7) and (8) can be solved for $x$ and $Y$. Note that for given $w, r$ and $\tau$, the $a_{i j}($.$) 's can be treated as fixed so that these are$ just straight lines as depicted in Figure 2. The solutions for the rest of the world, given $p^{* x}$ and the price of emissions denoted by $\tau^{*}$, can be analogously found. Finally, $\tau$ and $p^{* x}$ are determined by market clearing in the emissions market and in the world market for $x$ respectively. We turn to this below. 
Figure 2: Determination of Outputs

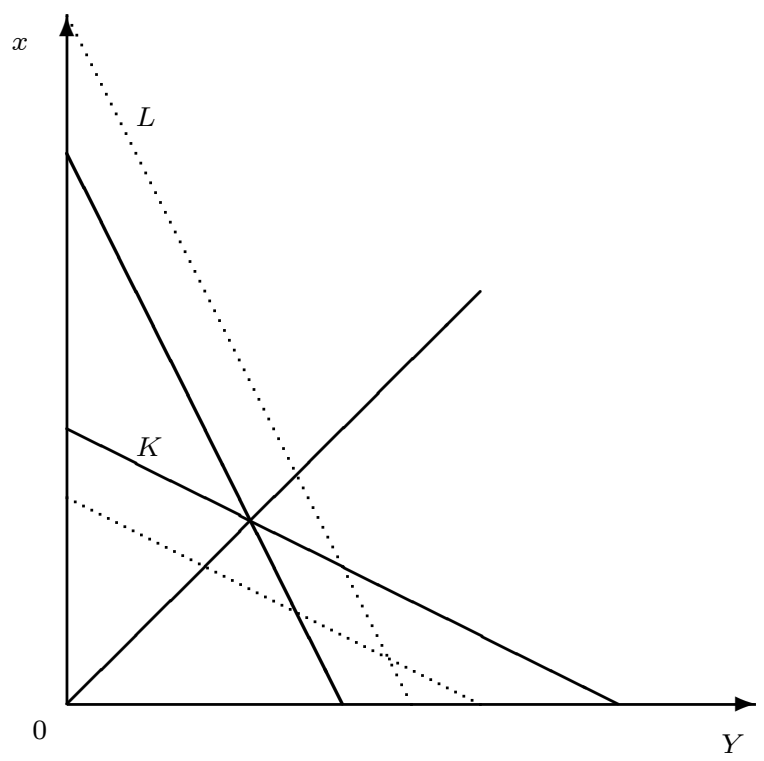

\subsection{Emissions Demand Given $p^{x}$}

The demand for emissions is a derived demand. It equals the product of the unit input requirement of emissions in making the dirty good $a_{Z x}($.$) , times$ the amount of the dirty good made, $x$, both of which we can solve for as above, given $\tau$ and $p^{* x}$. Since $x$ is made using $X$ and $Z, a_{Z x}($.$) will depend$ only on $\frac{c^{X}(w(.), r(.))}{\tau}$. Thus domestic emissions will equal

$$
Z^{D}(.)=a_{Z x}\left(\frac{c^{X}(w(.), r(.))}{\tau}\right) x .
$$

What can we say about $Z^{D}($.$) as a function of \tau$, taking as given $p^{x}$, the price facing producers, but with $w, r$ and $x$ being determined endogenously? How does $Z^{D}($.$) shift as p^{x}$ changes?

We will work through the model when $X$ is capital intensive relative to $Y$, or $k_{X}>k_{Y}$. As shown below, this is in no way crucial to the results and is merely assumed for concreteness. We will consider the case when the home country $(\mathrm{H})$ has a cap and trade program so that the domestic price of emissions, $\tau$, is positive, while the foreign country $(\mathrm{F})$ does not, so that the foreign price of emissions, $\tau^{*}$, is zero ${ }^{8}$.

\footnotetext{
${ }^{8}$ As is standard, we differentiate domestic variables from foreign ones by having the
} 
The demand for emissions remains downward sloping in $\tau$ for a given $p^{x}$ under fairly reasonable assumptions. $\tau$ affects the demand for emissions via its effects on $x$ and $a_{Z x}($.$) . First, consider its effect on x$. As only the dirty goods uses emissions as an input, an increase in $\tau$ (given $p^{x}$ ) reduces the competitiveness of $\mathrm{H}$ in the dirty good and thereby its output. ${ }^{9}$

What about $a_{Z x}($.$) ? If the dirty good is capital intensive (as would be$ the case if $k^{X}>k^{Y}$ ) the fall in $x$ due to the rise in $\tau$ releases more capital relative to labor than is used in $Y$. To absorb this excess capital, $r$ falls while $w$ rises which is what lies behind Figure 1 . As $X$ uses capital more intensively than $Y$, the fall in $r$ will reduce the cost of making $X$ and hence its equilibrium price. Thus, an increase in $\tau$ will raise $w$ reduce $r$, and reduce $p^{X}$. Consequently, as $\tau$ rises, $\frac{c^{X}(w, r)}{\tau}$ must fall, so there is substitution towards $X$ away from $Z$ in making $x$, i.e., a technique effect that makes $a_{Z x}($.$) fall as$ $\tau$ rises. ${ }^{10}$ Thus, the demand for emissions is decreasing in $\tau$ (for a given $p^{x}$ ) just like in partial equilibrium settings.

Given $p^{x}$, the equilibrium level of $\tau$ is determined by the intersection of the demand and supply of emissions. If emissions are limited, then supply is constrained at $\bar{Z}$ so that $\tau>0$. If emissions are not limited, then $\tau=0$ and emissions equal the demand for emissions at a zero price.

\subsubsection{Change in $p^{x}$ and Emissions Demand}

Next we turn to the effect of an increase in $p^{x}$, at a given $\tau$, on the demand for emissions. In other words, how does the demand for emissions shift as the price of the dirty good rises? We argue that the demand for emissions shifts outward as the price of the dirty good rises.

The increase in $p^{x}$ raises the output of $x$ via the usual positive supply response. This effect shifts out the demand for emissions. There is also a more subtle effect through factor prices. The increase in $p^{x}$ raises the price of the factor used intensively in $x$, so that if $x$ is capital intensive, $r$ rises

${ }^{9}$ The appendix shows more formally the conditions under which $x$ falls as $\tau$ rises for a given $p^{x}$.

${ }^{10} \mathrm{An}$ analogous argument shown that $a_{Z x}($.$) falls as \tau$ rises when the dirty good is more labor intensive as well. If the capital labor ratio in $X$ which is used in $x$ is less than that in $Y$ ) the fall in $x$ would release more labor relative to capital than is used in $Y$. As a result, $w$ would fall and $r$ would rise. As $X$ is labor intensive, its price wuld fall due to this change in $w$ and $r$. Consequently, as $\tau$ rises, $\frac{c^{X}(w, r)}{\tau}$ falls and there is substitution towards $X$ away from $Z$ in making $x, a_{Z x}($.$) falls as \tau$ rises.
} 
and $w$ falls ${ }^{11}$. As argued previously, this increase in $r$ raises the cost of $X$ and hence its price as the intermediate is capital intensive. Thus, for a given

$\tau, \frac{c^{X}(w, r)}{\tau}$ rises and due to the technique effect $a_{z x}\left(\frac{c^{X}(w, r)}{\tau}\right)$ rises as well for a given $\tau$. Thus, the demand for emissions must shift outward as the price of the dirty good rises.

A similar argument shows that the result is not dependent on the dirty good being capital intensive. If $x$ was more labor intensive than $Y$, then $w$ would rise which would raise the price of $X$ and reduce $r$. Once again, $a_{z x}\left(\frac{c^{X}(w, r)}{\tau}\right)$ would rise. Thus, whether $x$ is labor or capital intensive, both the normal supply response and the technique effect work to shift the demand for emissions outward and raise the equilibrium level of $\tau$ in response to an increase in $p^{x}$. Consequently, an increase in the world price of the dirty good serves to raise the price of emissions if $Z$ is exogenously set, and the equilibrium level of $Z$ if $\tau$ is exogenously set as when there are no emissions limits.

We now turn to the determination of $p^{x}$.

\subsection{Demand for goods}

World relative demand and relative supply determine $p^{x}$. As preferences are homothetic and $Y$ is the numeraire, relative demand for $x$ relative to $Y$ will depend only on $p^{x}$ and fall as $p^{x}$ rises.

\subsubsection{Determination of $p^{x}$}

Relative supply will similarly be increasing in $p^{x}$ due to the usual positive supply response. Their intersection determines the equilibrium level of $p^{x}$. This closes the model.

Figure 3 depicts the equilibrium in the emissions markets at the equilibrium world price. The base of Figure 3 gives total world emissions in the initial equilibrium. $\mathrm{H}$ limits its emissions at $O E$ and so has a emissions price of $P$. F has no emissions controls so that its emissions are $O^{*} E$ which generates a zero emissions price in $\mathrm{F}$.

\footnotetext{
${ }^{11}$ This is the Stolper Samuelson Theorem.
} 
Figure 3: Emissions Controls in General Equilbrium

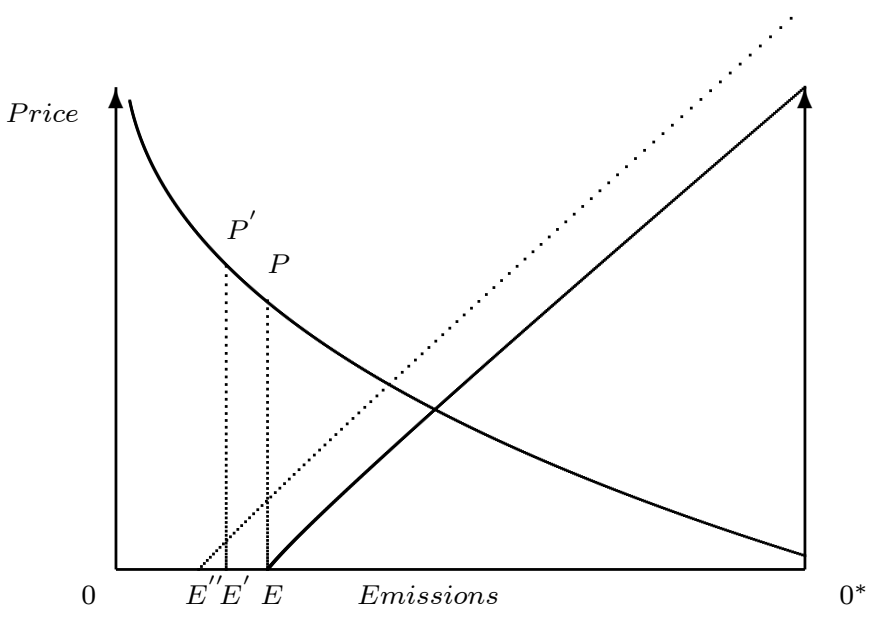

\subsection{Reducing Emission in $\mathbf{H}$}

Now we are ready to consider the effects of an exogenous reduction in the supply of emissions at home. Given $p^{x}\left(=p^{* x}\right)$, reducing $\bar{Z}$ from $O E$ in Figure 3 to $O E^{\prime}$ will raise the equilibrium level of $\tau$ to $P^{\prime}$. For a small country (one that cannot affect the world price) this is the end of the story. Its emissions fall and as the world price is unaffected, there is no effect on the demand for emissions in the rest of the world whose emissions remain at $O^{*} E$ and there is no leakage.

For a large country, however, this is not the end of the story. The rise in $\tau$ reduces the competitiveness of $H$ in $x$ and shifts the home and hence the world relative supply of $x$ inwards, thereby raising the equilibrium level of $p^{* x}$. This increase in $p^{* x}$ will shift the demand for emissions at home outward, further raising raise the equilibrium price of emissions at home, though $\mathrm{H}^{\prime} s$ total emissions will not change due to the change in $p^{x}$ as it has emissions controls. However, the increase in $p^{x}$ will shift the demand for emissions abroad outwards as depicted by the dashed curve in Figure 3. This shift will raise emissions abroad. It could even raise them more than emissions at home fell if $F$ used dirtier technology than $H$ overall as depicted in Figure 3 where $F$ emissions rise to $O^{*} E^{\prime \prime}$ from $O^{*} E^{\prime}$. World emissions rise as $O E^{\prime}+O^{*} E^{\prime \prime}$ 
exceeds $O E+O^{*} E$.

\section{Policy Implications}

A point made in the literature is that unilateral emissions reductions will be at least partly undone by leakage. In the context of the simple model above, this occurs through the increase in the equilibrium $p^{x}$ triggered by a fall in $\bar{Z}$. This increase in $p^{x}$ will shift the demand for emissions abroad outward and their equilibrium emissions, if they have no cap on total emissions, will rise. This "leakage" is the cause of much concern in the literature. However, note that if the rest of the world has caps on their own total emissions, even if these caps are just binding, then there will be no such leakage. With universal caps on emissions, a reduction in $\bar{Z}$ will raise the price of emissions everywhere and reduce world emissions one for one with the reduction in $\bar{Z}$. Consequently, the loss in competitiveness engendered by higher emissions prices in the country reducing emissions will be much less of an issue when all countries limit their emissions than when they do not and BTAs will also be less of an issue in terms of maintaining a level playing field.

The main point is that not just the level, but the existence of emissions controls in the rest of the world that matters. Getting the rest of the world to commit to controls on emissions, even if the level of emissions they commit to is high, is a step in the right direction as this affect the nature of international transmission. If the ROW has no controls on emissions, then $\tau^{*}$ is fixed (at a low number or zero) no matter what policy home enacts. Tighter emissions limits at home necessarily tilt the playing field in favor of $F$. But if the rest of the world has any limit on emissions, then tightening emissions at home will raise demand for emissions abroad and raise $\tau^{*}$, preventing leakage abroad, limiting the loss of competitiveness at home and making the home country more willing to reduce its own emissions.

If emissions are controlled only in a subset of countries, there will inevitably be leakage. How large might this leakage be? Trade theory has some insights to offer here. First, if some factors are mobile, and in today's world they seem to be increasingly so, factor mobility can make emissions controls much less binding. It is well understood by now, that attempts to tax trade will be undone by the movement of capital (i.e. firm location) in certain situations a la Mundell (1957). In a similar vein, taxing emissions will result in firm relocation if factors are mobile. This relocation could be very 
large depending on the setting and model used. Babiker (2005) produces estimates for leakage of over $100 \%$ in an oligopolistic model with increasing returns to scale when relocation is explicitly allowed for ${ }^{12}$.

How large leakage would be is ultimately an empirical matter. Hanna (2006), shows that US multinationals increased their foreign assets by about $5.3 \%$ and foreign output by about $10 \%$ in response to the Clean Air Act Amendment which dramatically strengthened US environmental regulations. Such responses even make things worse in terms of emissions if migrating firms use more polluting technologies abroad than at home. ${ }^{13}$

Recent work in trade, unrelated to the model above, may also be germane. A concern in, for example Mattoo et. al. (2009), is that BTAs imposed in order to level the playing field may have large effects on the exports of non emissions controlling developing countries. While competitive models would suggest that lower exports to the US when the US has BTAs could be made up by larger exports elsewhere, in monopolistically competitive settings, the opposite prediction exists. Lower exports to the US due to BTAs would be accompanied by lower exports to all other markets. This occurs because the fall in expected profits from the US reduces entry and as entry falls, sales to all markets fall. As a result, the short run effects, with entry held constant, are likely to be very different from the long run ones. It would be unfortunate if the adverse effects on developing country exports of BTAs were under-estimated.

\section{References}

Atkinson, Giles, Kirk Hamilton, Giovanni Ruta and Dominique van der Mensbrugghe (2009), "Trade in Virtual Carbon: Empirical Results and Implications for Policy", World Bank Policy Research Working Paper No. 5194. The World Bank, Washington, DC.

\footnotetext{
${ }^{12}$ In related work, Cherkashin et. al. (2010) show that in heterogeneous firm oligopolistic models, entry/exit by firms in response to trade policies are very large and account for most of the adjustment in output that occurs, suggesting that such settings might give large leakage effects in the emissions control context as well.

${ }^{13}$ In contrast, while examining the EU's emissions trading program, Grubb and Neuhoff (2006) argue that the net value at stake is low for most sectors as the cost increases by emissions trading in the 10 to 30 Euro range are small for all but a few industries. However, if firms are very responsive to such differences, even small changes could have large effects.
} 
Babiker, Mustafa (2005), Climate change policy, market structure, and carbon leakage, Journal of International Economics, 65, pp. 421-445.

Boehringer, Christoph; Fischery, Carolyn and Knut Einar Rosendahl (2010) "The Global Effects of Subglobal Climate Policies". Forthcoming, B.E. Journal of Economic Analysis and Policy.

Frankel, Jeffrey A. (2009). "Addressing the Leakage/Competitiveness Issue in Climate Change Policy Proposals". Brookings Trade Forum, 2008/2009, pp. 69-91. Brookings Institution Press.

Congressional Budget Office (2009) "The Economic Effects of Legislation to Reduce Greenhouse-Gas Emissions" September.

Cherkashin, Ivan, Demidova, Svetlana, Kee, H.L. and Kala Krishna. (2010) "Firm Heterogeneity and Costly Trade: A New Estimation Strategy and Policy Experiments." Mimeo, The Pennsylvania State University.

Congressional Budget Office (2009) "The Economic Effects of Legislation to Reduce Greenhouse-Gas Emissions" September.

Copeland, Brian and M. Scott Taylor. (2003) "Trade and the Environment: Theory and Evidence." Princeton University Press.

Grubb, Michael and Karsten Neuhoff (2006) "Allocation and Competitiveness in the EU Emissions Trading Scheme: Policy Overview. Climate Policy, Vol 6, pp. 7-30.

Hanna, Rema (2006). "US Environmental Regulation and FDI: Evidence from a Panel of U.S. Based Multinational Firms". Mimeo. Kennedy School of Government, Harvard University.

Mattoo, A., A. Subramanian, D. van der Mensbrugghe, and J. He, (2009). "Reconciling Climate Change and Trade Policy." Policy Research Working Paper WPS5123, Washington: The World Bank.

McKibben, Warwick and Peter Wilcoxen. (2008) "The Economic and Environmental Effects of Border Tax Adjustments for Climate Change Policy". (Mimeo)

Mundell, Robert A. (1957). "International Trade and Capital Mobility". The American Economic Review, Vol. 47, No 3, pp. 321-335.

\section{Appendix}

Result 1: Under reasonable conditions, an increase in $\tau$, given $p^{x}$, reduces $x$ and $a_{Z x}($.$) so that the demand for emissions is downward sloping while an$ increase in $p^{x}$ shifts out the demand for emissions. 
Proof: An increase in $\tau$ reduces what a firm making $x$ can afford to pay capital and labor which shifts back equation the curve representing (2) in $(w, r)$ space but leaves the curve representing (3) unaffected. This is depicted by the dashed curve in Figure 1 . As $x$ is capital intensive (since it uses $X$ which is capital intensive) this shift moves the intersection of the two curves up and to the left in Figure 1 and so reduces $r$ and raises $w$ assuming no specialization. As $r$ falls and $w$ rises and the price of $Y$ remains equal to its cost, the cost of $X$ must have fallen as $X$ is capital intensive. Thus, to keep price equal to cost, $p^{X}$ must fall.

As $w$ rises and $r$ falls due to the increase in $\tau$, unit labor requirements fall and unit capital requirements rise. Since $p^{X}$ falls when $\tau$ rises, $\frac{p^{X}}{\tau}$ falls so $a_{Z x}($.$) falls. This has implications for how equations ( 8) and (7) depicted$ in Figure 2 move as summarized below.

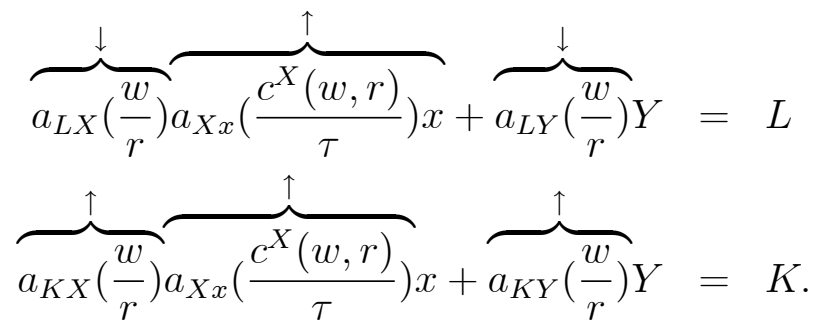

The coefficients of $x$ and $Y$ both rise in equation (8) so that in $x, Y$ space the line represented by equation (8) shifts inward. However, in $x, Y$ space the straight line representing equation (7) moves out only if $L$ and $K$ are more substitutable in making $X$ than are $X$ and $Z$ in making $x$ so that the effect of $a_{L X}$ falling dominates that of $a_{X x}$ rising and equation (7) moves out. This case is depicted by the dashed lines in Figure 2. In this case, a rise in $\tau$ must reduce $x$ and raises $Y$. Hence, fairly reasonable assumptions are sufficient for the demand function for emissions to be downward sloping. 